\title{
THEORETICAL AND PRACTICAL PRINCIPLES OF THE USE OF FAIRY TALE AT ENGLISH LESSONS A IN PRIMARY SCHOOL
}

\section{Olga Chorna ${ }^{1}$}

DOI: https://doi.org/10.30525/978-9934-588-38-9-20

\begin{abstract}
The subject of the study is an analysis of the practical results of using a fairy tale that is coherent in the content of narrative text in English lessons in elementary school. Methodology of the study. The following research methods were used to solve these tasks: a method of systematic pedagogical observation, the objectivity of which is provided by audio and video recording of lessons, extracurricular educational activities and other forms of activity of the students of the junior school; method of pedagogical experiment in the course of which innovative pedagogical phenomena are constructed, specified and tested; a method of analyzing the results of the activity, which allows to make an objective idea about the level of assimilation of the processed educational material; modeling method that serves to create and explore pedagogical models. The purpose of the study to substantiate the feasibility of engaging literary works in English lessons to consolidate vocabulary and grammar among elementary school students.
\end{abstract} Conclusions. It is quite difficult to master communicative competence in English without being in the country of the language being studied. Therefore, the important task of the educational process in English lessons in the beginning is to create real and imagined situations of communication using different methods. The publication proved that fairy tales contributes to: inclusion of children in the process of foreign language communication; formation of learning motivation; enhancement of foreign language educational and educational opportunities; development of cognitive interests and optimization of the educational process.

An analysis of the best pedagogical experience research has shown that a considerable number of scientist and academics have worked on the topic of active use of exercises with elements of fabulous literary works.

${ }^{1}$ Candidate of Pedagogical Sciences, Senior Lecturer,

Bohdan Khmelnytsky Melitopol State Pedagogical University, Ukraine 
In particular, the question of introducing fabulous works into the structure of foreign language lessons was covered in the works of our predecessors (O. Goncharov, L. Butenko, S. Nikolaev, O. Bigich, Z. Dikhtarenko, V. Kulish, O. Lyubchenko, N. Melianchuk, A. Shchukin, X. Henninger, Lipman, E. Taylor, etc.), who have published a number of interesting pedagogical innovations. The latter have hindered the increase of students' level of communicative competence in listening, speaking, reading and writing. The results of our formative experiment on the basis of Melitopol Secondary School I-III degrees № 14 (Melitopol, Zaporizhzhya region) in the 2nd grade prove that the work conducted with students on the basis of exercises with elements of fairy tales in the experimental group significantly improved the level of knowledge among schoolchildren (learning motivation appeared, foreign language educational opportunities increased, etc.)

Therefore, it can be said that the use of fairy tales in English lessons enhances students' cognitive activity, enhances their motivation and optimizes the learning process.

\section{Introduction}

Knowledge of foreign languages has always been highly valued in society. After all, knowing several languages broadens horizons, increases the efficiency of intellectual work, enriches the spiritual world of man and at the same time deepens the knowledge of the mother tongue. It is possible to assume that a person has mastered a language only when he / she successfully uses it in unprepared, spontaneous speech, without reliance on predefined language units.

Thus, the main purpose of learning a foreign language among students is to develop communicative competence, which involves not only the development of language skills, but also mastering the student's system of linguistic and socio-cultural knowledge. Interpreting texts and understanding the peculiarities of another culture in English lessons in elementary school is first and foremost helped by foreign-language folk tales, which are an indispensable means of generating positive motivation. After all, the tale opens the life of society and the environment to the child, explaining the world of human feelings and relationships. It develops the thinking and imagination of the child, enriches their emotions, has not only aesthetic, but also intellectual and cognitive value. The cognitive significance of the fairy tale is manifested 
primarily in the fact that it reflects the features of real life phenomena and provides valuable knowledge about the history of social relations, work and life, creates ideas about the worldview and psychology of the people, plots and images of oral folklore work include a broad typing in general.

A fairy tale teaches children courage, kindness, and other positive human qualities, but does so without tedious guidance, only demonstrating what can happen if a person does negative acts. The tale develops an aesthetic feeling, because it is characterized by the discovery of the beautiful in nature and man, the unity of the aesthetic and moral principles, the connection of the real and the fiction, vivid imagery and expressiveness. The fairy tale integrates knowledge about the peoples of the world, peculiarities of their communications, contributes to the formation of positive attitudes towards them. Children get acquainted with the common and special in different cultures, identify the leading features of ethnicity, such as: name, language, ethnic territory, anthropological type (appearance), highlight human values, and consider examples of mutual influence of cultures.

Relevance of the work is due to the need to clarify the theoretical foundations of fabulous works of fiction, as a special literary form in teaching English. The scientific novelty of the work is to formulate a theoretical justification for the need to use fairy tales that are holistic in content of text of narrative nature (theoretically united, informative, structurally organized) in English lessons in elementary school.

The purpose of the article was to theoretically substantiate the feasibility of using a fairy tale in English lessons for securing vocabulary and grammar among elementary school students, to experimentally test the effectiveness of the implementation of a special set of exercises. The goal is to solve the following important problems: to analyze the historiography of the problem; to find out psychological and pedagogical features of fairy tales in the process of teaching English; to explore the main ways to improve the methodology of teaching English with a fairy tale; to experimentally test the effectiveness of the use of language games and other collective exercises based on a fairy tale.

\section{Research methods}

The implementation of the tasks requires the use of the following methods of research: systematic pedagogical observation, pedagogical experiment, analysis of results of activity, modeling. 
The method of systematic pedagogical observation is the systematic and purposeful perception of pedagogical phenomena in order to study their specific changes in specific educational conditions. Using this method to study the external manifestations of feelings and behavior of children in different conditions of their life and reality. The scope of pedagogical observation is the realm of the educational process, in which it is intended to serve all pedagogical phenomena - from their inception to completion, from design to implementation, from diagnosis to counseling and practical assistance to students or their parents. The objectivity of the results from the involvement of systematic pedagogical observation is provided by audio and video recording of lessons, extracurricular educational activities and other forms of activity of the elementary school students.

The method of pedagogical experiment is one of the leading methods of pedagogical science, in the process of which innovative pedagogical phenomena are constructed, refined and tested. In the scientific practice of psychological and pedagogical research established rules of organization of pedagogical experiments. These include inadmissibility of risk to health and development of subjects, guarantees against damage to their health, from damage to life in the present and future.

The organization of the experiment also has methodological prescriptions, such as the search for an experimental base according to the rules of representative sampling, pre-experimental development of indicators, indicators, criteria and measures to evaluate the effectiveness of the impact on the results of training, education, development, drawing up hypothetical developments undergoing testing. Pedagogical experiment refers to complex research technologies, because it can be used in a variety of psychological and pedagogical methods, which include observation, interviews, interviews, questionnaires, diagnosing tasks, creating special situations, modeling and more. The choice of methods is determined by the content and nature of the set goals and objectives, methodological settings and specific conditions of the experiment. The hypothesis is tested for truth using specially selected (appropriate to the purpose and object) methods of research.

The method of analyzing the results of activities allows you to give an objective idea of the level of assimilation of the processed educational material. For example, the answers to the lessons characterize the student's memory, his / her thinking, imagination, views, beliefs. The creative works 
are the material for the conclusions about the focus of attention, observation, creative imagination, aesthetic feelings and artistic abilities of the student. In the diaries, students record certain events in their lives and attitudes toward them. Much information about the general development of the student, the culture of his speech, thinking, interests, ideological orientation provides the work. The teacher offers a subject that reveals the student's attitude to himself, his surroundings, the surrounding reality.

Modeling method is a method of creating and researching models. A scientific model is an imaginary or materially implemented system that adequately reflects the subject of the study and is capable of replacing it so that the study of the model facilitates the acquisition of new information about the subject. The main advantage of modeling is the ability to capture the system holistically. Simulation in pedagogy is successfully used to solve such tasks as improving the planning of the educational process, optimizing the structure of the educational material, managing cognitive activity, managing the educational process and so on. The modeling method is used to identify and classify new laws, construct new theories, and interpret the data obtained; to solve problems using models; to test a hypothesis using a particular model.

\section{Analysis of historiographical sources}

Practice proves that almost all educators and methodologists who work with children at different stages of learning English play a leading role literary works of fantasy. Some textbooks are entirely based on the use of fairy tales: their phonetic, grammatical and lexical features. Last but not least is the fact that fairy tales are an indispensable means of generating positive motivation for students, especially at the initial stage of learning [4, p. 119].

The analysis of historiographical sources proved that many domestic and foreign researchers worked on the problem of attracting fabulous works to the structure of foreign language lessons, among them: O. Goncharova, L. Butenko [4], S. Nikolaev, O. Bigich [12], Z. Dikhtyarenko, V. Kulish [5-6], O. Lyubchenko, N. Melianchuk [8-9], O. Shchukin, X. Henninger, Lipman, E. Taylor [14-17]. Despite the differences in teaching methodologies and technologies, these scholars have developed many valuable pedagogical innovations that have helped students achieve high levels of communicative competence in four activities: listening, speaking, reading 
and writing. Valuable methodical recommendations about the expediency of studying fairy tales at school can be found in the national magazines «English Language and Literature», «English in Primary School».

\section{Functional personalities and the potential of a fairy tale}

In literary sources, a fairy tale is defined as an oral folklore work that arose from the narrator's direct communication with the listener. It is a complete text of narrative nature, with a fictional (mostly fantastic story) that has the features of a coherent text: thematic unity, presence of title, actionable completeness, informative presentation, structural organization (communication between parts), conversational style of language, etc. [7, p. 345].

In their entirety, fairy tales are divided into folk (folk) and author's tales. Folk tales in their early period existed and were transmitted orally, giving them special characteristics that facilitated their rapid and comprehensible literary adaptation. These include: chronological sequence of actions, repetitions, predictability of events, simple grammatical basis, wide common vocabulary, etc. In addition, a large number of fairy tales have rhyme shapes, which in turn can be used in processing accent and rhythm during pronunciation training.

At the turn of the XX-XXI centuries, the author's fairy tale became especially popular, which took on new forms in order to meet the demands of time, but at the same time it does not lose its close connection with folklore. This is probably because contemporary fairy-tale writers bring their own works closer to the original linguistic and cultural environment of the country they came from. An important condition for the creation of an author's work is its compliance with the laws of fairy tale construction, the absence of personal unconscious projections of the author in it, the possibility of reproduction of the most bizarre story options, openness of material and accessibility of language constructions, the relevance of life collisions, the presence of a classic emotional scheme: culmination, denouement.

Reflecting on the origin of the fairy tale, scientists assumed that in folk works to a certain extent reflected the symbolic content of ancient beliefs and rituals, the most important of which was the initiation (overcoming various difficulties, the fairy tale hero was given the opportunity to change - the transition to another qualitative level). Well-known Russian Slavist V. Propp wrote: «The general question is: where does the tale come 
from? Just as rivers flow into the sea, all questions of fairytale study should ultimately lead to the knowledge of the most important and still unsolved problem - the similarity of fairy tales across the globe. How to explain the similarity of the tale of the royal frog in Russia, Germany, France, India, America in the Indians and New Zealand, and the historical communication of peoples can not be proven?» [13, p. 27].

The first scientific theories on the problem of fairy tales date back to the XVIII century. And it is not only a purposeful collection of folk tales, made, for example, by the brothers J. and V. Grimm in Germany, and S. Perrot in France, but also attempts to interpret their content. Differences in views, about theories of the origin of fairy tales emerged in the XIX century. In particular, scientists pointed to three main points of view on this problem: the «Indian version», according to which all the main fairy tales and images were born in India and later spread to Europe (T. Benfey); The «Babylonian Version», which claimed that Babylon was the birthplace of fairy tales, and the crossing point on their journey to Europe was the Asia Minor Peninsula (A. Jensen, H. Winkler, E. Pieces); A version of many centers, which insisted on the impossibility of indicating one particular place of birth of all tales, which speaks of the emergence of different tales in different countries (the «Finnish school» founded by K. Kron and A. Aarn) [11, p. 63-64].

From the beginning of the twentieth century, the similarity of fairy tales in different peoples was explained by scientists for the following reasons: 1) the similarity of living conditions in different peoples - separated from each other by space and time, however, having homogeneous results independently of their development; 2) the similarity of fairy tales in the Aryo-European peoples can partly be explained by the preservation of individual tribes of the poetic traditions that were once the common heritage of the Aryo-European race before its disintegration into separate tribes; 3 ) the similarity of the tales of Aryo-European peoples of other races can be explained also by mutual borrowing, carried out under the influence of peaceful and military relations of different races. Transitions of fairy tales from one people to another, of course, were accompanied by their change and mixing with each other. Therefore, today it is difficult to distinguish between a fairy tale in a fairy tale and a borrowed one: it is difficult to tell fairy tales in their stories and decoration with an international character, with a slight layer of national imprint. 
Thus, the problem of the universal identity of fairy tales remains crucial to the humanitarian knowledge of the 21st century. Traditions of folklore folklore were able to significantly advance the historical, linguistic and ethnographic understanding of this genre of verbal creativity, allowed to determine the fairy tale a powerful source of cognitive, emotional and moral development of man.

In folklore, the most popular classification is the division of folk tales into the following types: animal tales; fairy tales with mythological meaning; household fairy tales.

To the tales of animals include such folklore works, in which the characters are wild animals, less - domestic animals. It can be assumed that such tales originated in an era when basic pursuits forced people to often encounter animals, in the era of hunting and animal husbandry. Due to poor weapons, the man seemed to be weak in comparison to a number of carnivorous animals. Because of this, individual animals seemed to her extremely powerful. Under the influence of an animistic worldview, people attributed human abilities to beasts, and in exaggerated dimensions: for example, the cry of a beast or a bird was incomprehensible to humans, but human language to beasts and birds was understandable; animals knew more than humans and understood their aspirations. In the era of animal husbandry there was a conviction of man in the possibility of turning it into a beast. The rise in human power gradually diminished these views and beliefs, which eventually reflected on the content of fairy tales about animals.

The main characters of Ukrainian fairy tales were mostly forest animals - foxes, wolves, bears, hares, as well as domestic animals - goats, bulls, horses, dogs, cocks etc. Most often, foxes and wolves became heroes of fairy tales about animals. This was explained by the fact that it is often a person to face in economic activity. It is known that the fox became the leading hero of the folk epic in Western Europe. In France, this epic was called Roman de Renart, and in Germany - Reinhart Fuchs. Both in the Western European animal era and in the Eastern Slavic, the fox was equally beastly shrewd, treacherous, cunning, thereby gaining an advantage over other animals stronger than she - over, for example, the wolf and the bear.

In Ukrainian fairy tales, the fox had different nicknames: kuma-fox, fox-sister and so on. The wolf acted in fairy tales with other traits: evil, greedy, voracious, but silly and imprudent; the fox often jokes about him 
and deceives him, but the wolf is exposed to its tricks every time. Thus, the wolf and the fox acted in fairy tales with characteristic features. Much less had a bear: his main feature was credulity and naivety.

Fairy tales with mythical representations are folk tales depicting the struggle of light supernatural forces with the dark, which from an animistic point of view symbolized the change of seasons, day and night, etc. But of course, in fairy tales with mythical content, the struggle of light and dark was determined by means of fantastic images. The fading of nature in the fall and winter was represented in the form of the abduction of beauties by monsters, dragons, or in the form of a lull, petrified, charming girls. The fogs and clouds that covered the sun and prevented its impact on earthly nature were embodied in the image of the Serpent; cold and cold were represented in the form of Frost or, Koshcha-soulless; winter, forcing nature to ossify, represented in the image of the Witch.

The main characters of these tales, as a rule, set themselves the goal of returning the stolen beauties or reviving them, if they petrified, fell asleep, etc., that is, the revival of nature. This goal was achieved with the help of special amazing objects or creatures: golden apples, deer-golden horns, fire-birds, etc., which represented the golden rays of the sun; often in fairy tales the dead and the living water, which deadens and then invigorates, are mentioned - it is the dew, spring and summer rains that animated nature; Samothran tablecloth - an image of generosity that occurs in nature in the spring and summer.

Household tales are called such folklore works, which reflected the features of folk life. They can be divided into two directions: the first include fairy tales in which there are traces of mythical or ancient views; the second includes fairy tales, which observe Christian views and which date back to the later era. Household tales include the following topics: unequal but happy marriage, stepdaughter and stepmother, younger brother and older brothers, or sister and more.

\section{The impact of fairy tales on children's outlook}

Of course, traditional education contrasts the tale with imperative knowledge. But a fairy tale for a child is not just a literary work, it is an acceptable and consonant with the capabilities of the child a means of materializing his troublesome relationships and circumstances, the constitution of customs 
and the set of laws of existence, rules of cohabitation and norms of delicacy, categories of good and evil, multipolarity and relativity of social evaluations. A fairy tale for a child is an amazing tool for working with the inner world of the child, a powerful tool for development.

Fairy tales describe the in-depth experience of experiencing emotional crises that are characteristic of a developing person. This can be a direct bodily experience associated with the passage of psychophysiological processes. Influenced at an unconscious level, fairy tales include adequate mechanisms for protecting the individual, including adaptation processes that help overcome the crisis.

Some scholars (Sh. Buhler), studying the role of fairy tales in the development of a child, emphasized that the characters of folk tales are often simple and typical, devoid of any individuality; sometimes they do not even have names, and their characteristics are limited by two or three qualities that are understood by the child's perception. However, these characteristics are brought to the absolute: they have unprecedented kindness, courage, ingenuity. At the same time, the fairy tale characters do everything ordinary people do: eat, drink, work, marry, and so on. All this contributes to a better understanding of the story of the child.

Adding that, when playing crisis life situations, a fairy tale teaches a child to productively experience and overcome fear, directing and projecting fear into specific fairy-tale images. However, the events and images of the fairy tale not only project on the real life situation of the listener and reproduce in a metaphorical form moral norms and principles of relationships between people, but also include the deep mechanisms of the unconscious due to unusual archetypal elements of the mind [2, p. 14].

Thus, the fairy tale satisfies three important natural psychological needs of the child: the need for autonomy (independence), because in each fairy tale the hero acts independently, relying on his own strength; the need for competence (power, omnipotence), because the hero is able to overcome the most incredible obstacles, is a winner, succeeds; need for activity (the hero is always in action).

A significant factor in the perception of the fairy tale is its visual adaptation. After all, fairy tales are often published in children's books with color illustrations, which further reveal the content of the submitted literary material. Folk tales are connected not only with national literature, but also 
with religion, history, sociology and as a whole act as an effective means of personal education [14, p. 258].

An important literary technique in a fairy tale is the utterance when ordinary people with their real life problems emerge after extraordinary fairytale characters or animals. The adventures of fairy-tale heroes hide human destinies, true life stories, complex household and social relationships. An unknown speaker of the folk tale tells the audience about the difficult choice of the right path, the bitterness of solitude and the sincerity of friendship. In a fairy tale, children are confronted with such complex phenomena and feelings as life and death, love and hate, betrayal and treachery.

The literal meaning of the fairy tale is perceived by the consciousness, while at the same time the subconscious is engaged in a more complicated matter: solving and processing metaphorical messages, deciphering the hidden meaning, the background, and the non-obvious content. If at a conscious level the child perceives fairy-tale metaphors as another, fictional world and lives its events not quite seriously, as if playing, then his subconscious «believes» in fairy-tale situations as real. Thus, the fairy tale shapes the child's need for a high moral attitude to the surrounding world [9, p. 42-45].

It should be emphasized that any fairy tale is focused on socio-pedagogical effect: it teaches, encourages activities and even heals. In other words, the potential of a fairy tale is much greater than its ideological and artistic significance. From a socio-pedagogical point of view, certain functions performed by a fairy tale are important. Among them are the following: a socializing function (attracting new generations to universal and ethnic experiences, the means of the international world of tales); creative function (helps to identify the ability to form, develop and realize the creative potential of the individual, his imaginative and abstract thinking); holographic function (manifested in three main forms - the ability of the fairy tale in the small to see large; the ability to represent the universe in three-dimensional spatial and temporal dimensions; the ability of a fairy tale to actualize all organs of human senses, to be the basis for creation of all kinds, genres, types of aesthetic creativity; developmental-therapeutic function (fosters a healthy lifestyle, prevents the child from pernicious hobbies, passions, etc.); cultural and ethnic function (draws on the historical experience of different peoples, their ethnic culture - life, language, traditions). 
The lexical-figurative function, that is, the formation of the linguistic culture of the individual, the possession of polysemy and the artistic-figurative richness of the language.

\section{Theoretical and practical results of the study}

A fairy tale transmitted in a foreign language also has enormous educational opportunities. In its best images and plots, it opens the student to the outside world, conveys the essence of human relations and feelings - kindness, respect, compassion, society, justice, sensitivity, understanding - thus enriching the moral potential of the child [4, p. 119]. The composition of a fairy tale, the striking juxtaposition of good and evil in its content, fantastic images, expressive language, the dynamics of events, special cause and effect relationships and phenomena - all this is widely available to the student's understanding, and therefore makes fairy tale an indispensable tool for the formation of morally healthy personality.

According to the Ukrainian scientist G. Galushka, when choosing a fairy-tale piece in elementary school, it is necessary to take into account not only the psychological and age characteristics of students, but also to adhere to certain pedagogical criteria. First of all, you should choose small authentic fairy tales (without a great artistic context), saturated with socio-cultural information with accessible lexical and grammatical material. Give preference to literary storytelling, in which the plot is able to quickly attract the attention of children and engage them in the process of listening, reading, discussion. The fairy tale should correspond to the language material of the curriculum and the basic principles of learning a foreign language. In particular, how fully during the work with folk art works can be realized the basic didactic (strength of the acquired knowledge, clarity, consciousness and activity of educational training, etc.) and methodical (communicative, taking into account the peculiarities of the native language, interrelated learning of different types of speech activity).

It should be emphasized that the working principle of educating conscious learning is effectively implemented on the basis of fairy tales: the ability to work, to cultivate love and respect for work is formed, there is a need for creative work, such human qualities as patience, perseverance, inquisitiveness, willingness to come. Also present in the fairy tale is the aesthetic component of the educational aspect - attraction to beauty and development of 
good taste. As researcher M. Vaskov rightly pointed out, positive emotional actions occurring in a fairy tale help to prevent feelings of distrust in children, a hostility that often appears, for example, in adults, as a natural reaction to a new, unfamiliar, unusual, falling outside the usual social relations [1, p. 112].

Through the introduction of fairy tales in foreign language lessons, students become interested in the lives of peoples of other countries. After all, in the younger school age, the cognitive aspect plays an important role: the child's interest in the cultural heritage of the language being studied is formed and realized. Tale-based learning provides an opportunity to learn about elements of national culture.

In fairy tales there is always a pronounced socio-cultural component. The inseparable connection of a fairy tale with life enables elementary school students to gain experience, both linguistically and socially, in life through situations, subjects of discussion that are present in a fairy tale work. Interest in the unknown in the younger students allows you to use in the classroom and apply a wealth of regional studies (information on history, geography, life, traditions, interests of their peers; information about music, painting, symbolism, clothing, holidays, etc.). Of great importance in the context of fairy tales are the literary forms of oral folk art, such as songs, poems, counters, games, etc., which act as an active basis for communication in English.

Fairy tale is effectively used in solving problems of a purely educational nature. In particular, speaking individual lexical forms based on folk narratives forms students' perceptions of English as a means of communication. It is known that the training of students in the use of grammatical structures, requires their spaced repetition, which tire children with their monotony. A fairy tale, in turn, can make monotonous work more interesting and exciting. On the basis of the story-based literary work you can build a variety of situations of role-playing communication, story-role-playing games, dialogues and more. Thus, the fairy tale contributes to the formation of motivation of learning, enhances the educational and educational opportunities of a foreign language, acts as an effective means of teaching foreign language communication.

When drafting texts of folk tales in English lessons, it is generally recommended to use three types of exercises: receptive, productive, mixed.

Receptive exercises are aimed at combining visual perception with speech communication. For example, choosing from a number of drawings those 
that match the content of the fairy tale; placing the drawings in a sequence corresponding to the unfolding of the plot; marking the movement of fairy tale characters on the map and more. In the course of their work, students are introduced to the basic terms that they are supposed to operate, suggest to define the genre of fairy tales and the main elements of the plot of folklore work. This type of work, according to the already mentioned scientist G. Galushka, contributes to the implementation of cross-curricular relations, the formation of a serious attitude to the processing of fairy tales (analyze the work of art, distinguish in it the main structural elements). In the future, the main elements of the plot are presented to students in the form of a scheme that promotes the generalization of information heard and has benefits for students with a predominant visual type of perception [3, p. 67].

Productive exercises are a type of educational activity that combines oral and written forms of work. For example, the story of Ukrainian and other national tales in English; development of the plot according to the child's own imagination, writing fairy tales on a given subject [10, p. 218]. The latter kind of work is not typical enough: students write fairy tales on their own (if desired, draw illustrations for them). Written works can be designed as a collection, at the beginning of which is to place information about the authors, as well as their photos. Such attention to the child will not only contribute to the development of speaking skills and analytical skills, but also allows students to enjoy the results of their own work.

Mixed - receptive-productive exercises also play an important role: auditioning or comprehending the beginning of a fairy tale, predicting its completion and comparing predictions with the original ending; writing a sequel to a read fairy tale; drawing up a fairy tale plan; selection of repeating structural and content blocks in a fairy tale; placement of major events in chronological order; a transfer on behalf of one of the characters; playing dialogues between fairy-tale characters; comparing English folk tales with Ukrainian or with national tales of other nationalities [10, p. 213-214].

An experimental verification of the effectiveness of the implementation of the set of exercises we developed to improve the level of students' knowledge and their active activity at the elementary school lesson was conducted on the basis of grade 2-A of Melitopol Secondary School I-III grades № 14 (Melitopol, Zaporizhzhya region). The school has two training profiles: information technology and legal. The educational insti- 
tution tries to keep up with the times, acquires new positive changes, goes through new stages of development.

The number of students who took part in the experiment was 23 children. The class was divided into two groups: experimental - 12 students and control -11 .

Our set of exercises included the use of language games and other collective exercises based on a fairy tale, in order to provide children with the opportunity to get new information, to discover the world of interesting English. The lessons of English in these groups were given by one teacher, who used a common textbook (O. Karpiuk, «English language: 2nd grade, Ternopil, 2012) and printed workbooks (O. Karpiuk, N. Kohut), «English»: 2nd grade, Ternopil, 2009). According to the criteria for assessing the academic achievement of foreign language students in the elementary education system, there were 4 levels: high, sufficient, medium and low (according to the State standard and the program for learning English for the 2nd class).

When familiarizing with the receptive grammatical material, we followed the following sequence of methodical actions: presentation of new grammatical material on the blackboard; consideration of a new grammatical phenomenon based on the analysis of several written texts; formulation of a rule that includes an indication of the formal and substantive features of the new grammar material. The results of the work are shown in table 1.

Table 1

Levels of cognitive activity of students

\begin{tabular}{|c|c|c|}
\hline Levels & Experimental group & Control group \\
\hline High & 3 & 3 \\
\hline A sufficient & 3 & 4 \\
\hline Average & 3 & 3 \\
\hline Low & 3 & 1 \\
\hline Total & 12 & 11 \\
\hline
\end{tabular}

As you can see, the results obtained indicate a revival of cognitive activity of students, an increase in the level of their cognitive activity. Therefore, I propose to compare the results of the results before the implementation of the forming experiment and after its start in percent in table 2. 
Table 2

Comparison of cognitive activity of students

\begin{tabular}{|c|c|c|c|c|}
\hline \multirow[b]{2}{*}{ Levels } & \multicolumn{2}{|c|}{ Prior to implementation } & \multicolumn{2}{|c|}{ After implementation } \\
\hline & $\begin{array}{c}\text { Experimental } \\
\text { group \% }\end{array}$ & $\begin{array}{c}\text { Control group } \\
\%\end{array}$ & $\begin{array}{l}\text { Experimental } \\
\text { group \% }\end{array}$ & $\begin{array}{c}\text { Control group } \\
\%\end{array}$ \\
\hline High & $25 \%$ & $25 \%$ & $35 \%$ & $25 \%$ \\
\hline Sufficient & $25 \%$ & $40 \%$ & $35 \%$ & $40 \%$ \\
\hline Average & $25 \%$ & $25 \%$ & $20 \%$ & $25 \%$ \\
\hline Low & $25 \%$ & $10 \%$ & $10 \%$ & $10 \%$ \\
\hline Total & $100 \%$ & $100 \%$ & $100 \%$ & $100 \%$ \\
\hline
\end{tabular}

The design experiment made it clear that in the control group the parameters had not changed. But there are changes in the experimental group, they have improved significantly. One student remained low, though there were three at the beginning of the experiment. This is $25 \%$ of the total. The average level decreased by $5 \% .4$ students have a sufficient level. This is $35 \%$ of the total. 4 students have a high level, which means $35 \%$ of the total.

\section{Conclusions}

It is quite difficult to master communicative competence in English without being in the country of the language being studied. Therefore, the important task of the educational process in English lessons in the beginning is to create real and imagined situations of communication using different methods and techniques.

An analysis of best pedagogical experience has shown that a considerable number of teacher educators have worked on the topic of active use of exercises with elements of literary works of fantasy In particular, the question of introducing fabulous works into the structure of foreign language lessons was covered in the works of our predecessors (O. Goncharov, L. Butenko, S. Nikolaev, O. Bigich, Z. Dikhtarenko, V. Kulish, O. Lyubchenko, N. Melianchuk, A. Shchukin, X. Henninger, Lipman, E. Taylor, etc.), who have published a number of interesting pedagogical innovations. The latter have stepped up to increase students' level of communicative competence in listening, speaking, reading and writing.

The publication proved that the fairy tale contributes to: inclusion of children in the process of foreign language communication; formation of 
learning motivation; enhancement of foreign language educational and educational opportunities; development of cognitive interests and optimization of the educational process. The results of our formative experiment on the basis of Melitopol Secondary School I-III degrees №14 (Melitopol, Zaporizhzhya region) in the 2nd grade prove that the work carried out with students on the basis of exercises with elements of fairy tales in the experimental group significantly improved the level of knowledge among schoolchildren (there was a motivation to study, increased foreign language educational opportunities, etc.).

Therefore, it can be said that the use of fairy tales in English lessons enhances students' cognitive activity, enhances their motivation and optimizes the learning process.

\section{References:}

1. Vaskov M. (2008). Celebrate with us!: scenes, holidays, scenes, fairy tales, games, competitions, competitions eng. language, director's advice. Kharkiv: Torsing Plus. (in Ukrainian)

2. Vachkov I. (2011). Introduction to fairy-tale therapy. Moscow: Genesis. (in Russian)

3. Galushka G. (2008). Forming sociocultural competence through fairy tales. Kharkiv: The Basis. (in Ukrainian)

4. Goncharova O., Butenko L. (2013). The use of folklore in foreign language lessons. Glukhiv Scientific Readings - 2013: Proceedings of the Third International Scientific Conference of Young Scientists and Students. Hlukhiv, p. 119.

5. Dikhtarenko Z. (2008). Upbringing of Junior Pupils' Persistence in the Process of Out-of-School Playing Activity (PhD Thesis). Kyiv: Inst. of problems of education of APS of Ukraine.

6. Kulish V. (2009). Fascinating English. Dnipro: Stalker. (in Ukrainian)

7. Yartseva V. (ed.) (2001). Linguistic Encyclopedic Dictionary. Moscow: Enlightenment. (in Russian)

8. Lyubchenko O. (2005). Non-standard English lessons. Kharkiv: Basis. (in Ukrainian)

9. Melianchuk N. (2007). Extracurricular activities in English in elementary school. Family holidays. Kharkiv: Basis. (in Ukrainian)

10. Nikolaeva S. (ed.) (2002). Methods of teaching foreign languages in secondary schools. 2nd, vypr. and recycling. Kiev: Lenwith.

11. Mikhalchenko K. (2011). Psychological fairy tale as a means of selfconsciousness development. Young scientist, vol. 2(12), pp. 62-66.

12. Nikolaeva S., Bigich O. (2002). Methods of teaching foreign languages in secondary schools: [textbook for students of higher educational establishments], 2nd species. Kiev: Lenwith. (in Ukrainian) 
13. Propp V. (1998). Morphology. Historical roots of a fairy tale. Moscow: Labyrinth. (in Russian)

14. Shchukin A. N. (2004). Foreign Language Teaching: Theory and Practice: [Textbook for Teachers and Students] 2nd ed., Ispr. and ext. Moscow: Filomatis. (in Russian)

15. Henninger N. (2005). The Didactic Functions of Storytelling in the Primary School Classroom. Munich: GRIN Verlag.

16. Lipman D. (2003). Improving Your Storytelling: Beyond the Basics for All Who Tell Stories in Work or Play. Little Rock: August House.

17. Taylor E. (2005). Using Folktales. Cambridge: Cambridge University Press. 